\title{
On the limiting aerodynamic roughness of the ocean in very strong winds
}

\author{
M. A. Donelan, ' B. K. Haus, ' N. Reul, ${ }^{2}$ W. J. Plant, ${ }^{3}$ M. Stiassnie, ${ }^{4}$ H. C. Graber, \\ O. B. Brown, ${ }^{1}$ and E. S. Saltzman ${ }^{5}$
}

Received 9 January 2004; accepted 13 August 2004; published 28 September 2004.

[1] The aerodynamic friction between air and sea is an important part of the momentum balance in the development of tropical cyclones. Measurements of the drag coefficient, relating the tangential stress (frictional drag) between wind and water to the wind speed and air density, have yielded reliable information in wind speeds less than $20 \mathrm{~m} / \mathrm{s}$ (about 39 knots). In these moderate conditions it is generally accepted that the drag coefficient (or equivalently, the "aerodynamic roughness") increases with the wind speed. Can one merely extrapolate this wind speed tendency to describe the aerodynamic roughness of the ocean in the extreme wind speeds that occur in hurricanes (wind speeds greater than $30 \mathrm{~m} / \mathrm{s}$ )? This paper attempts to answer this question, guided by laboratory extreme wind experiments, and concludes that the aerodynamic roughness approaches a limiting value in high winds. A fluid mechanical explanation of this phenomenon is given. INDEX TERMS: 4504 Oceanography: Physical: Air/sea interactions (0312); ‘4560 Oceanography: Physical: Surface waves and tides (1255); 4894 Oceanography: Biological and Chemical: Instruments and techniques; 3307 Meteorology and Atmospheric Dynamics: Boundary layer processes; 3339 Meteorology and Atmospheric Dynamics: Ocean/atmosphere interactions $(0312,4504)$. Citation: Donelan, M. A., B. K. Haus, N. Reul, W. J. Plant, M. Stiassnie, H. C. Graber, O. B. Brown, and E. S. Saltzman (2004), On the limiting aerodynamic roughness of the ocean in very strong winds, Geophys. Res. Lett., 31, L18306, doi:10.1029/ 2004 GL0 19460.

\section{Introduction}

[2] The mechanical coupling of atmosphere and oceans is at the heart of modeling the flow of either fluid, of predicting their future states and of understanding the long-term development of climate. In strong winds the mechanical (frictional) coupling between air and sea depends almost entirely on the geometric roughness of the sea surface and the relative speed between the near surface winds and the waves (roughness elements) that determine the evolving topography. A flat calm surface exhibits only

\footnotetext{
${ }^{1}$ Rosenstiel School of Marine and Atmospheric Science, University of Miami, Mianni, Florida, USA.

${ }^{2}$ Institut Français de Recherche pour l'Exploitation de la Mer, Plouzane, Fiance.

${ }^{3}$ Applied Physics Laboratory, University of Washington, Seattle, Washington, USA.

${ }^{4}$ Faculty of Civil Engineering, Technion Israel Institute of Technology, Haifa, Ismel. USA.

"Earth System Science, University of Califormia, Irvine, California,
}

Copyright 2004 by the American Geophysical Union. 0094-8276/04/2004GL019460\$05.00 molecular or "skin" friction with the following air: On the other hand, a wave travelling at lower speed than the wind nay disturb the air flow in such a way as to produce a pressure difference between the windward and leeward faces of the wave. This "form" drag clearly depends on the elevation change of the surface per unit horizontal distance; i.e., the slope of the wave. It further depends on how quickly the wave travels relative to the wind: a slow moving wave causes great resistance to the air, while one that approaches the wind speed "goes along for the ride" and thus sheds its function as a drag element. The sustained action of wind on a water surface gives rise to a spectrum of waves. On an open ocean surface an increasing wind develops a spectrum of waves (called "wind-sea") with increasing spectral width, the longest waves always attempting to catch up to the wind. These large waves can and do reach lengths of hundreds of meters and heights of tens of meters, remaining in that rough proportion: height/wavelength $\sim 1 / 10$. Waves that are much steeper than this will be brought back into line by the process of wave breaking, in which the water at the crest of the wave exceeds the speed of travel of the wave form and tumbles down the forward face of the wave in a "spilling breaker". The distortion to the smooth wave shape caused by breaking presents to the wind a backward facing (downwind) step, which makes it difficult for the air flow to follow the surface, leading to separation of the flow from the surface.

[3] The general practice is to estimate the interfacial stress (vertical transport of horizontal momentum, $T$ ) with a wind-speed dependent drag coefficient, $C_{D}$ :

$$
T=\rho_{a} C_{D} U_{10}^{2}
$$

where $\rho_{a}$ is the air density and $U_{10}$ is the wind speed measured at $10 \mathrm{~m}$ height. $C_{D}$ is a function of sea state, atmospheric stability, height of measurement of the wind speed and the wind speed itself. In fact, in moderate and high wind conditions the wind stress is supported by form drag of the roughness elements, namely waves that travel at significantly different velocities than the wind. In open ocean conditions, the stronger the wind, the wider the spectrum of waves that travel at slower speeds than the wind. Consequently the drag coefficient increases as the wind speed increases. The data supporting these wind speed dependent drag coefficients cover a relatively small range of wind speeds, typically 4 to $20 \mathrm{~m} / \mathrm{s}$, with relatively few data points above $15 \mathrm{~m} / \mathrm{s}$. Is it reasonable to extrapolate these simple height and wind speed dependent drag coefficients $\left(C_{D}(\mathrm{u}, \mathrm{z})\right)$ to very high winds for modelling severe extra tropical cyclones and hurricanes?

[4] A negative answer to this question is suggested by analytic energy balance models [Emanuel, 1995] and also 


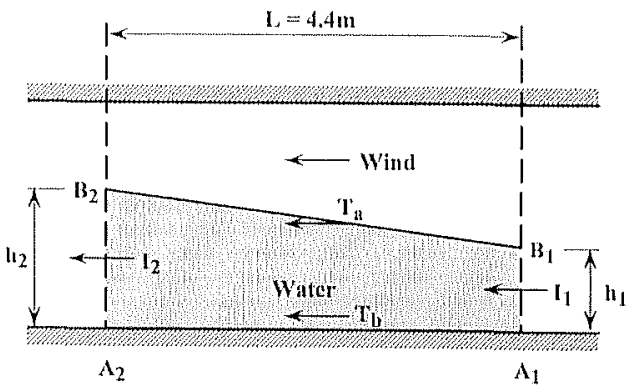

Figure 1. Schematic outline of the control volume for the momentum budget.

by the recent measurements of wind profiles in hurricanes [Powell et al., 2003]: the high frictional coupling suggested by extrapolating wind speed dependent empirical drag coefficients destroys the hurricane's kinetic energy faster than it can be supplied by reasonable oceanic heat sources for wind speeds above about $50 \mathrm{~m} / \mathrm{s}$ [Emanuel, 1995]. Thus, if the drag coefficient does continue to increase with wind speed at high winds, intense hurricanes (category III and above, $\mathrm{U}_{10}>50 \mathrm{~m} / \mathrm{s}$ ) cannot be sustained. The existence of such storms belies the assumed coupling and raises the intriguing possibility of a marked change in character of the mechanical coupling of air and sea in hurricane conditions. Emanuel [2003] invokes a similarity hypothesis to suggest that at high wind speeds the exchange coefficients become independent of the gradient wind. However, simulations and comparisons with four hurricanes suggest only that the wind dependence of the coefficients of momentum and enthalpy must be similar.

[5] In very strong winds the character of the ocean surface does change appreciably having intense breaking, spume blown off the crests of waves and streaks on the surface. Given these general changes in the surface, one may expect a qualitatively different behaviour in its frictional properties than that suggested by observations in moderate wind conditions. In the following we explore these issues in a controlled laboratory environment.

\section{The Experiment}

[6] The Air-Sea Interaction Facility at the University of Miami is especially well suited for examining the effects of high winds. The centerline wind speed can be programmed in the range of 0 to $30 \mathrm{~m} / \mathrm{s}$. The tank is $15 \mathrm{~m}$ long in its working section and $1 \mathrm{~m}$ wide with its height of $1 \mathrm{~m}$ divided equally between air and water. The tools for measuring stress include hot-film anemometry, digital particle image velocimetry (DPIV) and laser/line scan cameras for measuring the water surface elevation with great precision, about $10^{-4} \mathrm{~m}$. Two elevation measurements over $10 \mathrm{~m}$ thus yield slope precision of $10^{-5}$.

[7] The principal difficulty with direct ("eddy correlation" or "Reynolds") stress measurements at high wind speeds using hot-film anemometry is the likelihood of spray droplets falling on the heated films, corrupting the velocity data and possibly causing damage to the films. Therefore, we measured the Reynolds stress directly with an $x$-film anemometer at low and moderate (centerline) wind speeds $(0$ to $26 \mathrm{~m} / \mathrm{s}$ ). We determined the stress at the measured elevations and corrected the values to the surface with the measured horizontal pressure gradient in the tank. In addition, at higher winds we determined the surface stress from a momentum budget of sections of the tank. The wind stress at the surface, in steady state conditions, increases the momentum of the wave field with increasing fetch, drives a downwind current near the surface and thereby maintains a downwind slope of the mean surface (mean surface elevation increasing in the downwind direction). The horizontal pressure gradient, thus induced, drives a return flow (upwind flow) in the bottom of the water column. This return flow causes a drag on the bottom of the tank. Finally, the horizontal pressure gradient in the air that produces the wind adds to the slope of the water surface - the "inverted barometer" effect.

\section{Momentum Balance in the Water}

[8] The momentum budget is balanced over a control volume, which is $4.4 \mathrm{~m}$ long (between the fetch of $4.6 \mathrm{~m}$ and the fetch of $9.0 \mathrm{~m}$ ), and extends from the tank bottom up to the interface between water and air, over the width of the tank $(1 \mathrm{~m})$.

[9] The control volume is defined by the shaded area, $A_{1}$ $B_{1} B_{2} A_{2}$ and unit width into the page in Figure 1. Applying the horizontal impulse-momentum principle on the water within the control volume, and averaging over time leads to a balance of four terms

$$
\mathrm{I}_{2}-\mathrm{I}_{1}=\mathrm{T}_{\mathrm{a}}+\mathrm{T}_{\mathrm{b}}
$$

$I_{2}$ and $I_{1}$ are the momentum fluxes through sections $A_{2} B_{2}$ and $A_{1} B_{1}$, respectively; $T_{a}, T_{b}$ are the stresses applied by the air and the tank bottom on the water.

[10] From water-wave theory it is known that

$$
I=\frac{1}{2} \rho_{w} g h^{2}+P h+S_{x x}
$$

where $\rho_{w}$ is the density of water, $g$ is the gravitational acceleration, $h$ is the time averaged water depth, and $P$ is the pressure of the air. The radiation stress $S_{x x}$ for deep water is

$$
S_{x x}=\frac{1}{2} \rho_{w} g \iint \Phi(f, \theta) \cos ^{2} \theta d f d \theta
$$

where $\Phi$ is the frequency-direction spectrum of the waves and $\theta$ the angle of wave propagation relative to downwind.

[11] It is easily shown that the wind stress is given by:

$$
\tau=h\left(\rho_{w} g s+\frac{\Delta P}{L}\right)+\frac{\Delta S_{x x}}{L}-\tau_{b}
$$

where $h=\left(h_{1}+h_{2}\right) / 2$ is the averaged water depth, $\Delta \mathrm{P}=$ $P_{2}-P_{1}$ is the air pressure difference, $\Delta S_{x x}=\left.S_{x x}\right|_{2}-\left.S_{x x}\right|_{1}$ is the radiation stress (4) difference, and $s=\left(h_{2}-h_{1}\right) / L$ is the slope of the surface. The bottom stress $T_{b}$ is measured with the DPIV system using the law of the wall.

[12] In our calculations we have ignored the sidewall stresses. Their magnitude is of the same order as that of the bottom stress, which was always found to be less than $2 \%$ of the total. Furthermore, in the steady state there is no net 


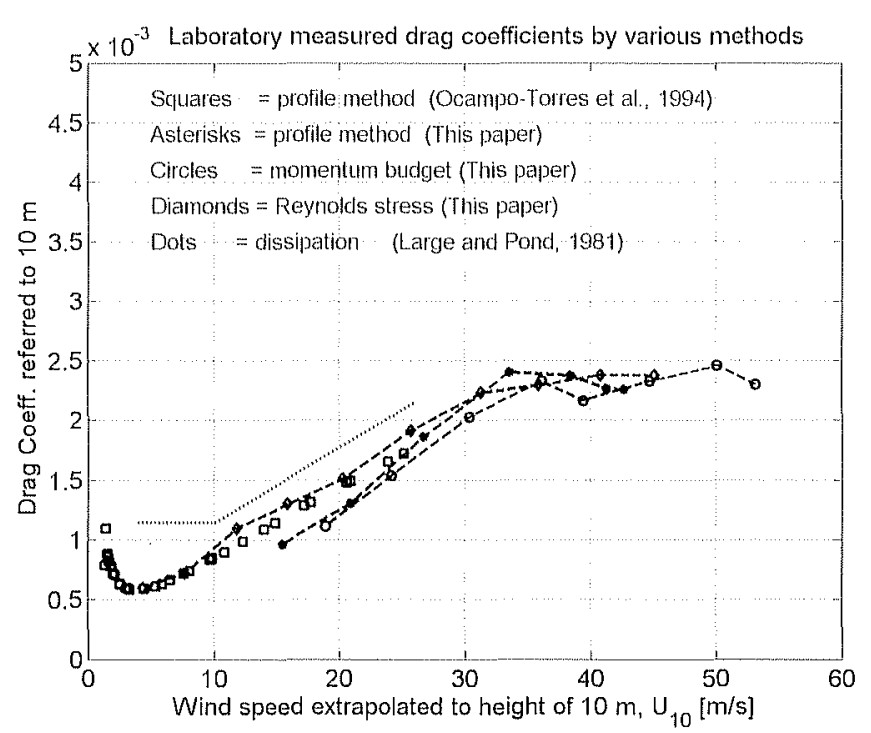

Figure 2. Laboratory measurements of the neutral stability drag coefficient by profile, eddy correlation ("Reynolds") and momentum budget methods. The drag coefficient refers to the wind speed measured at the standard anemometer height of $10 \mathrm{~m}$. The frequently cited drag coefficient formula of Large and Pond [1981] is also shown. This was derived from field measurements.

mass transport so that the sidewall stresses change sign over the water column (in keeping with the wind drift and its opposing return flow) and tend to cancel out.

[13] Spray droplets accelerated in the air flow and returned to the surface contribute to the stress on the surface. Some of this spray was blown into the return duct at high winds and thus represents a loss of stress. On the assumption that all of the water lost from the tank was in the form of spray travelling at the wind speed, we calculate a generous upper limit of $1.5 \%$ lost momentum due to spray.

[14] Several experiments were carried out with the wind, which was driven by a programmable fan, set to fixed speeds for 300 second runs. This was long enough to obtain a stable estimate of the stress.

\section{Results}

[15] The measurements of the drag coefficient (1) referred to wind speed at $10 \mathrm{~m}$ are summarized in Figure 2. The wind speed was measured at $30 \mathrm{~cm}$ height in the tank and extrapolated to the standard meteorological height of $10 \mathrm{~m}$ using the well established logarithmic dependence on height - verified between crest height and $30 \mathrm{~cm}$ for all but the two highest wind speeds. The green squares were obtained in a different tank by Ocampo-Torres et al. [1994]. The other three data sets were obtained in the Air-Sea Interaction Facility of the University of Miami using the profile method (in which the vertical gradient of mean horizontal velocity is related to the surface stress), the Reynolds stress method, and the momentum budget or "surface slope" method. The excellent agreement among the various methods validates the momentum budget method which, being insensitive to air-borne droplets, allows us to measure the surface stress at the highest winds generated. Here we see the characteristic behaviour of the drag coefficient as the surface condition goes from aerodynamically smooth (characterized by a drop in the drag coefficient with increasing wind) to aerodynamically rough (drag coefficient increasing with wind speed). In rough flow the drag coefficient is related to height of the "roughness elements" per unit distance downwind or, more precisely, the spatial average of downwind slope. Unlike a solid surface, the roughness elements (or waves) are themselves responsive to the wind so that the drag coefficient increases between 3 and $33 \mathrm{~m} / \mathrm{s}$ as shown in Figure 2 .

[16] In hurricanes the wind speed changes direction and speed over relatively short distances compared to those required to approach full development. Consequently, the largest waves in the wind-sea are relatively slow compared to the wind and often travel in directions different from that of the wind. Under such circumstances these long waves contribute to the aerodynamic roughness of the sea as hypothesized by Kitaigorodskii [1968] and demonstrated by Donelan [1990]. Measurements at sea [e.g., Large and Pond, 1981] and in laboratories [e.g., Donelan, 1990; Ocampo-Torres et al., 1994] amply demonstrate the increasing aerodynamic roughness with increasing wind speed. However, no in situ Eulerian measurements of the surface stress, $\tau$ or roughness, $z_{0}$ have been reported at wind speeds above $30 \mathrm{~m} / \mathrm{s}$ in the field or $20 \mathrm{~m} / \mathrm{s}$ in linear wind wave tank laboratory facilities. The recent Lagrangian measurements [Powell et al., 2003] using air-dropped GPS wind sondes provide wind profiles along the (non-vertical) path of the falling sondes. The estimates of surface stress made from these "profiles" is subject to the assumption of constant stress over the vertical extent of the profile, about $150 \mathrm{~m}$.

[17] Figure 2 shows a remarkable "saturation" of the drag coefficient once the wind speed exceeds $33 \mathrm{~m} / \mathrm{s}$. Beyond this speed the surface simply does not become any rougher in an aerodynamic sense. At the highest wind speed the significant height and peak frequency of the waves were $9 \mathrm{~cm}$ and $1.4 \mathrm{~Hz}$. In the range of wind speeds of 10 to $26 \mathrm{~m} / \mathrm{s}$ our measurements parallel the open ocean measurements of Large and Pond [1981], but are a little lower. Our measurements suggest aerodynamic roughness saturation beyond $10 \mathrm{~m}$ height wind speeds of $33 \mathrm{~m} / \mathrm{s}$. The saturation level for the drag coefficient is 0.0025 . This corresponds to a roughness length of $3.35 \mathrm{~mm}$. An adjustment to agree with Large and Pond [1981] would suggest saturation at 0.0028 , and the wind sonde profiles of Powell et al. [2003] show "saturation" of the drag coefficient at 0.0026 at about $35 \mathrm{~m} / \mathrm{s}$."

\section{Discussion}

[18] The possibility of a limiting state in the aerodynamic roughness of the sea surface is of critical importance in understanding and modelling the development of hurricanes and other intense storms. Our results suggest a change in flow characteristics leading to saturated aerodynamic roughness at boundary layer wind speeds in excess of $33 \mathrm{~m} / \mathrm{s}$ or about 64 knots. This approaches Force 12 on the Beaufort Scale [Allen, 1983], wherein conditions are described as follows: "Hurricane. The air is filled with foam and spray. Sea completely white with driving spray - visibility very seriously affected." Figure 3 illustrates these conditions with a photograph from a NOAA "Hurricane Hunter" aircraft. 


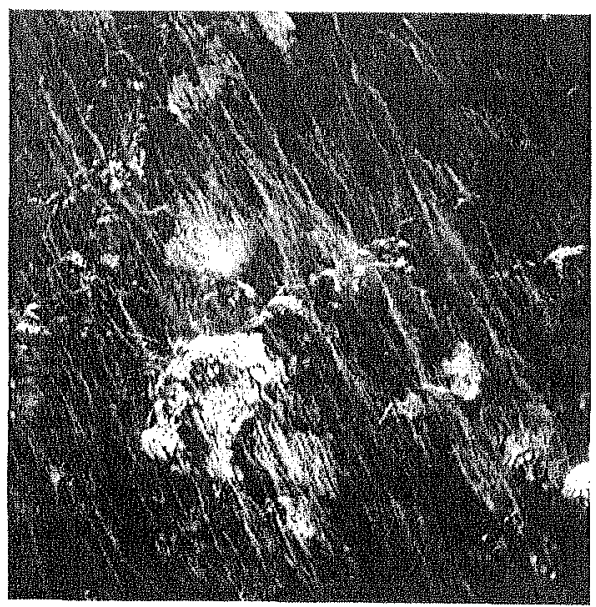

Figure 3. Photograph of the sea surface during a hurricane (Beaufort Force 12) taken from a NOAA "Hurricane Hunter" aircraft [Black et al., 1986].

[19] When the wave crests are blown into spume, does this signal a fundamental change in flow characteristics of fast moving air over much slower waves? The recent work of Reul [1998] and Reul et al. [1999] appears to illuminate this issue. Vorticity contours, observed by particle image velocimetry using water droplets as tracers (Figure 4), reveal the flow pattern of wind over waves that are steep but not breaking (top) and the flow pattern over a spilling breaker (bottom). When the wave is not breaking and the spatial rate of change of slope (i.e., curvature) is not large the vorticity pattern indicates that the strongest shear occurs very near the surface. On the other hand, a breaking wave, with abrupt change in slope (large curvature of a backward facing step type), causes the flow to separate from the surface and reattach near the crest of the preceding wave. The vorticity contours show a distinct maximum well above the surface of the wave trough, indicating a shear layer between the outer flow and the flow trapped in the separation zone. The outer flow, unable to follow the wave surface, does not "see" the troughs of the waves and skips from breaking crest to breaking crest. Thus, in conditions of

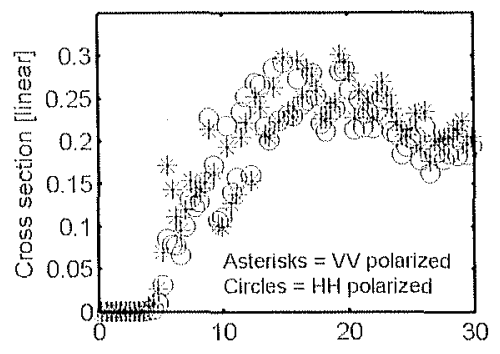

Figure 5. Normalized radar cross section (NRCS) versus centerline $(0.3 \mathrm{~m}$ height $)$ wind speed in the tank. Note that $\mathrm{U}_{10}$ is approximately $1.5 \mathrm{U}_{0.3}$

continuous breaking of the largest waves the aerodynamic roughness of the surface is limited, the geometric roughness of the large waves notwithstanding.

[20] Microwave radars ("scatterometers") are commonly used to deduce marine wind speeds from received backscatter and hence the reflectivity of short capillary-gravity waves $(1 \mathrm{~cm}$ to $10 \mathrm{~cm}$ ). Consequently it is of great practical importance to examine the radar response in these high wind conditions. Microwave reflectivity measurements in our tank indicate that the geometric roughness of the short (centimetric) waves also decreases at sufficiently high wind speeds. The microwave cross section at $\mathrm{C}$-band $(5.3 \mathrm{GHz})$ looking upwind at $35^{\circ}$ incidence angle reaches a maximum at the wind speed where the drag coefficient stops increasing (Figure 5). This indicates that the small-scale geometric roughness does not continue to increase with wind speed. When the outer flow no longer "sees" the troughs of the long waves, it is unable to generate small-scale roughness there, reducing the overall microwave reflectivity.

[21] The reduced reflectivity of the air-water interface measured by scatterometers and the observations of flow separation in laboratory work indicate a plausible mechanism for the limiting aerodynamic roughness observed in this laboratory study. The profile measurements of Powell et al. [2003] support the idea that a similar limit to the aerodynamic roughness of the real ocean may also occur in high winds.
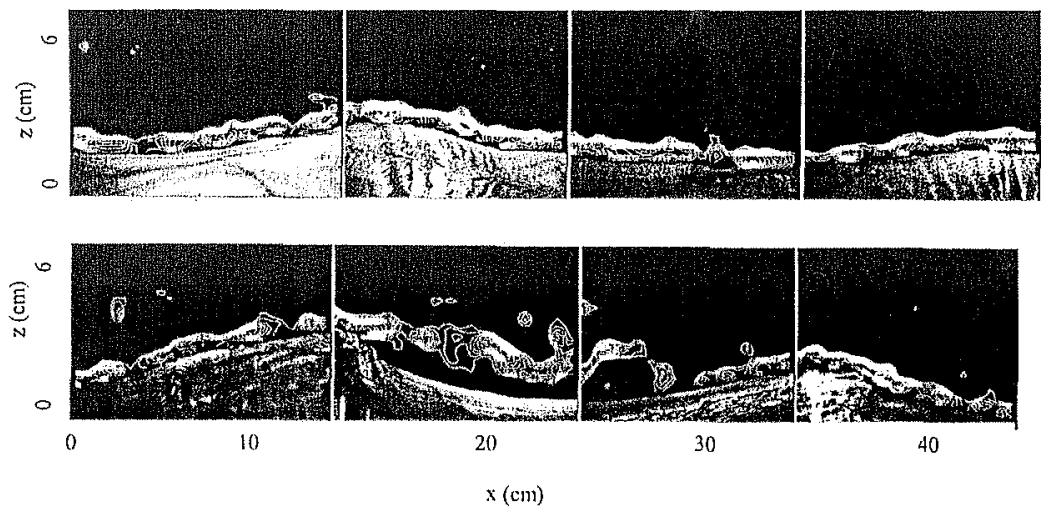

Figure 4. Vorticity contours obtained via Digital Particle Image Velocimetry (DPIV) in the air flow over wind driven waves [Reul, 1998]. Both wave propagation and air flow are from left to right. (Top) waves of gentle slope - non-separated flow. (Bottom) waves of steep slope - separated flow. 
[22] Acknowledgment. We thank F. Dobson and G. Golitsyn for helpfin discussions, and acknowledge the stipport of the Office of Naval Research under grant number N000|40310567.

\section{References}

Allen, W. T. R. (1983), Wind and sea: Stale of sea photographs for the Beaufort Wind Scale, 57 pp., Atmos. Enviton. Serv., Environ. Can., Ollawa, Ontario.

Black, P. G., R. W. Burpee, N. M. Dorst, and W. L. Adams (1986), Appearance of the sea surface in tropical cyclones, Weather Forecasting, I, $102-107$

Donelan, M. A. (1990), Ait-sea interaction, in The Sea, vol. 9, Ocean Engineering Science, edited by B. LeMehaute and D. M. Hanes, p). 239-292, Wiley-Interscience, Hoboken, N. J.

Emanuel, K. A. (1995), Sensitivity of tropical cyclones to surface exchange coefficients and a revised steady-state model incorporating eye dynamics, J. Almos. Sci, 52, 3969-3976.

Emanuel, K. A. (2003), A similarity hypothesis for air-sea exchange at extreme wind speeds, $J$. Atmos. Sci., 60, $1420-1428$.

Kitaigorodskii, S. A. (1968), On the calculation of the alerodynamic roughness of the sea surface, Izv. Russ. Acad. Sci. Almos. Oceanic Plys., Engl. Transl., 4, 498-502.

Large, W. G., and S. Pond (1981), Open ocean momentum flux measurements in moderate to strong winds, J. Phys. Oceanogr:, //, 324-336.
Ocampo-Torres, l: J., M. A. Donclan, N. Merzi, and F. Jia (1994), Laboratory measurements of mass transfer of carbon dioxide and water vapour for smooth and rough flow conditions, Tellus, Se: B, 46, 16-32.

Powell, M. D., P. J. Vickery, and 'T. A. Reinhold (2003), Reduced drag coefficient for high wind speeds in tropical cyclones, Nature, 422, 279283.

Reul, N. (1998), Etude expérimentale de la structure de l'écoulement d'air au-dessus de vagues courtes déferlantes, Ph.D. Uhesis, 334 pp., Univ de la Mediteranee, Marseille, France.

Reul, N., H. Branger, and J.-P. Giovanangeli (1999), Ail flow separation over unsteady breaking waves, P/ys. F/uids, 1/, 1959-1961.

O. B. Brown, M. A. Donelan, H. C. Graber, and B. K. Haus, Rosenstiel School of Marine and Atmospheric Science, University of Miami, Miami, FL 33149, USA. (mdonelan@rsmas.miami.edu)

W. J. Plant, Applied Physics Laboratory, University of Washington, Seattle, WA 98105, USA.

N. Reul, Institut Français de Recherche pour l'Exploitation de la Mer; F- 29280 Plouzane, France.

E. S. Saltzman, Earth System Science, University of Califonia, Irvine, Irvine, CA 92697, USA.

M. Stiassnie, Faculty of Civil Engineering, Technion Israel Institute of Technology, Haifa 32000, Israel. 